\title{
Extração e Caracterização de Xilanas de Sabugos de Milho.
}

\author{
Simone S. Silva, Rosiane R. Carvalho, José Luis C. Fonseca e Rosangela B. Garcia
}

\begin{abstract}
Resumo: Neste trabalho, duas frações de xilana, denominadas xilana A e xilana B, foram isoladas a partir de sabugos de milho através de três processos diferentes, combinando métodos de extração aquosa, remoção de lipídeos, deslignificação e extração alcalina. Os produtos obtidos durante os processos foram analisados por termogravimetria. A etapa de deslignificação foi responsável por uma acentuada degradação dos polímeros, evidenciada por queda de rendimento e resistência térmica. Os espectros obtidos no infravermelho evidenciaram a ausência de ácidos urônicos na cadeia polimérica. As viscosidades intrínsecas obtidas para a xilana A $(56 \mathrm{~mL} / \mathrm{g})$ e xilana B $(75 \mathrm{~mL} / \mathrm{g})$ associadas aos resultados do infravermelho sugerem um número maior de grupos substituintes, constituídos basicamente por resíduos de L-arabinose, para a xilana B.
\end{abstract}

Palavras-chave: Xilana, hemicelulose, polissacarídeo, deslignificação.

\section{Introdução}

A parede celular dos vegetais pode ser considerada um compósito polimérico constituído, basicamente, por celulose, pectina, lignina e um grupo de polissacarídeos denominados hemiceluloses, que caracteriza-se pela sua insolubilidade em água e solubilidade em soluções alcalinas. O termo hemicelulose foi atribuído a esses polissacarídeos por Schulze, em 1891, devido à sua forte associação com a celulose ${ }^{[1]}$.

A natureza química das hemiceluloses ainda não se encontra devidamente esclarecida. Sabe-se, entretanto, que são na sua maioria heteropolissacarídeos constituídos por unidades repetidas de pentoses (Dxilose e L-arabinose), hexoses (principalmente Dgalactose, D-glicose e D-manose) e ácidos urônicos ${ }^{[2]}$. Existem evidências de que, em média, o número de polissacarídeos diferentes, caracterizados como hemicelulose nas espécies vegetais, não excede a três ou quatro, e que os polissacarídeos denominados xilanas ou heteroxilanas, formados por unidades de D-xilose ligadas por pontes glicosídicas $\beta-1 \rightarrow 4$ na cadeia principal e diferentes carboidratos, tais como ácidos urônicos e seus derivados, L-arabinose e oligossacarídeos em cadeias laterais ${ }^{[1-5]}$, como mostra a Figura 1, são frequientemente encontrados como principais constituintes das hemiceluloses em muitas espécies vegetais. No caso específico dos sabugos de milho, tem sido considerado que as xilanas que os constituem apresentam, em geral, uma estrutura química formada por ácido 4-O-metil-D-glucurônico, Larabinose e D-xilose, na proporção 2:7:19 ${ }^{[1,6]}$.

Nos últimos anos, têm surgido evidências de que as arabinoxilanas (xilanas que possuem grande número de resíduos de arabinose em cadeias laterais), contidas nos grãos de cereais, encontram-se interligadas

Simone S. Silva, Rosiane R. Carvalho, José Luis C. Fonseca e Rosangela B. Garcia - Departamento de Química, Universidade Federal do Rio Grande do Norte, Caixa Postal 1662, CEP 59078-970, Natal, RN, e-mail balaban@linus.quimica.ufrn.br. 


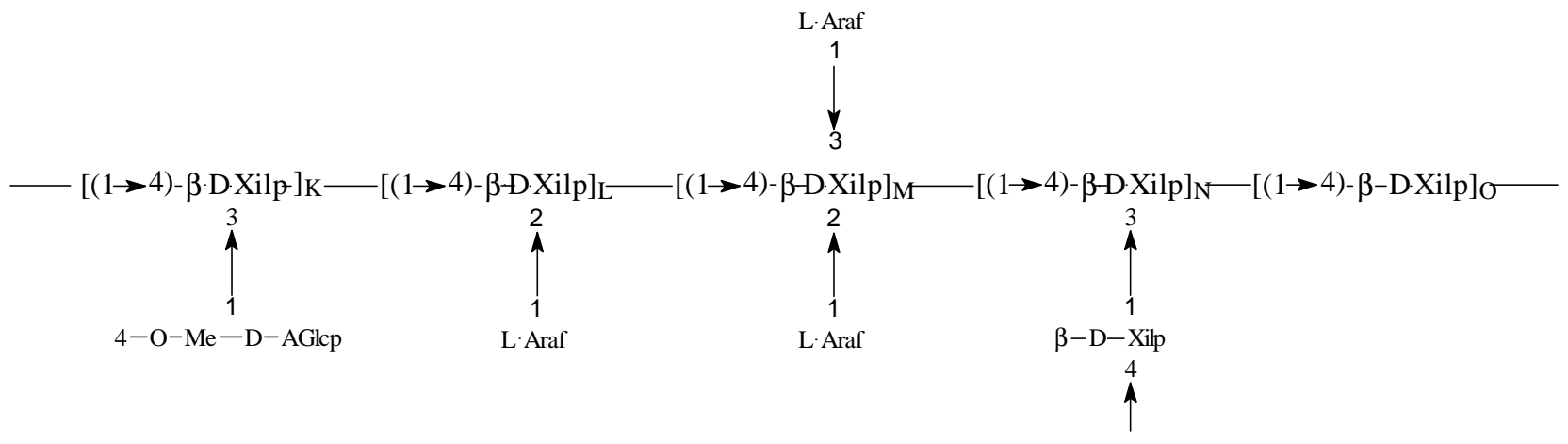

Figura 1. Estrutura química das xilanas.

na parede celular através de ligações cruzadas, ocorridas por esterificação com o ácido diferrúlico (Figura 2), e/ou pela formação de complexos com proteínas ${ }^{[7-10]}$. Essas estruturas seriam responsáveis pela dificuldade de extração e purificação das xilanas, assim como pelo tempo de digestão dos grãos de cereais ${ }^{[8-10]}$.

As xilanas têm sido pouco utilizadas industrialmente. As aplicações mais importantes encontram-se na produção do furfural ${ }^{[11]}$ e do papel ${ }^{[1]}$, onde elas são processadas sob a forma bruta. A presença de cerca de $5 \%$ de hemicelulose na polpa da madeira resulta em um papel de melhor qualidade, com maior resistência mecânica. Em produtos alimentícios, sabe-se que as xilanas presentes nas farinhas de trigo apresentam grande importância no cozimento e maciez das massas, devido à capacidade que possuem de reter água ${ }^{[12,13]}$, e que reduzem significativamente o envelhecimento do produto, por interações específicas com o amido ${ }^{[14]}$.

Recentemente, a quaternização de xilanas extraídas de sabugos de milho, através de reações com cloreto de 3-cloro-2-hidroxipropil-trimetil-amônio (CHMAC), apresentou como resultado boa atividade antimicrobiana a baixo grau de substituição, alcançando resultados superiores aos observados para o brometo de cetil-trimetil-amônio (CTAB ${ }^{[15]}$.

Neste trabalho é apresentado um estudo da extração e algumas propriedades das xilanas presentes nos sabugos de milho, visando adquirir maior conhecimen-

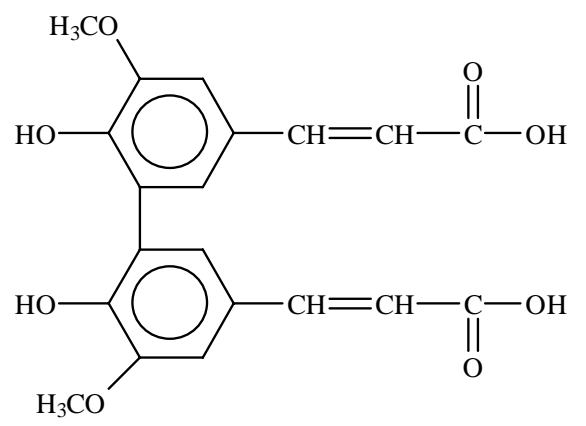

Figura 2. Estrutura química do ácido diferrúlico. to sobre esses biopolímeros, encontrados em quantidades significativas nos rejeitos de agricultura sem valor comercial e que podem apresentar um grande potencial de utilização como materiais biocompatíveis na indústria médico-farmacêutica.

\section{Experimental}

\section{Isolamento das xilanas}

Inicialmente, os sabugos de milho foram expostos ao sol por 48 horas para secagem. Em seguida, foram triturados em um moinho e tamisados através de uma série de peneiras Tyler. As frações de diâmetro médio $0,37 \mathrm{~mm}$, contendo $9,4 \%$ de umidade, foram submetidas a diversos tratamentos, como descrito a seguir.

\section{Extração aquosa}

O material triturado foi submetido a uma extração aquosa na proporção de 30 gramas de pó de sabugo para $1000 \mathrm{~mL}$ de água destilada, sob agitação constante, durante uma noite e à temperatura ambiente. A mistura foi então centrifugada, e a fase sólida seca à pressão reduzida por 24 horas.

\section{Remoção de lipídeos}

O material resultante da extração aquosa sofreu remoção de lipídeos através de uma mistura azeotrópica de benzeno-álcool etílico (razão benzeno/ álcool etílico $(\mathrm{v} / \mathrm{v})=2: 1)$ em extrator Soxhlet, durante 24 horas.

\section{Deslignificação}

Após a secagem do material obtido anteriormente, o mesmo foi submetido à deslignificação por um 
processo organosolve, considerando a sua eficiência de remoção da lignina descrita na literatura ${ }^{[16,17]}$. Cerca de 10 gramas de amostra foram dispersas em 1000 $\mathrm{mL}$ de mistura constituída por $97 \%$ de 1,4-dioxano e $3 \%$ de ácido clorídrico. O sistema foi mantido sob agitação e à temperatura ambiente por períodos que variaram de 1 a 4 horas.

Ao término da deslignificação, a solução foi filtrada, e o resíduo contendo xilana foi lavado diversas vezes com 1,4-dioxano e em seguida com água destilada, apresentando um $\mathrm{pH}$ em torno de 1 . O resíduo foi disperso em água destilada, sendo em seguida neutralizado com solução aquosa de hidróxido de sódio $4 \%$, até alcançar o valor de $\mathrm{pH}=7,0$. A solução foi centrifugada e o resíduo seco sob vácuo.

\section{Extração alcalina}

A solubilização das xilanas foi feita através de tratamento alcalino do pó de sabugo com $\mathrm{NaOH} 4 \%$, a temperatura ambiente. Foi utilizada uma proporção de 10 gramas de pó para $200 \mathrm{~mL}$ de solução. O sistema foi mantido sob agitação constante por 5 horas. Após filtração a vácuo, a solução foi neutralizada através da adição de ácido acético glacial, até alcançar o valor de $\mathrm{pH}=7,0$. Nessa fase, foi observado o aparecimento de precipitado no meio, que foi atribuído à xilana denominada xilana A. Após centrifugação, essa fração de xilana sofreu diversas lavagens com álcool etílico e, em seguida, foi seca sob vácuo.

A xilana contida no filtrado (xilana B) foi precipitada pela adição de álcool etílico, na proporção de três volumes de álcool para 1 volume de solução. $\mathrm{O}$ produto obtido foi centrifugado e lavado diversas vezes com álcool etílico.

A Figura 3 apresenta um esquema simplificado do processo utilizado para o isolamento das xilanas, mostrando que, ao todo, foram obtidas 6 amostras, através da solubilização das xilanas em diferentes fases do processo.

\section{Testes de solubilidade}

A solubilidade dos polissacarídeos denominados na Figura 3 por xilana A. 2 e xilana B. 2 foi testada em soluções aquosas de uréia a 2, 4 e $6 \mathrm{~mol} / \mathrm{L}$, e ainda em vários solventes orgânicos, como piridina, N,Ndimetil-acetamida (DMA), dimetil-sulfóxido (DMSO), clorofórmio, cloreto de metileno/cloreto de etileno (2:1). Amostras dos polímeros, pesando cerca de $0,05 \mathrm{~g}$, foram dispersas em $10 \mathrm{~mL}$ de solvente, sob agitação constante e temperatura ambiente, por uma noite. A classificação da solubilidade foi feita através da mas-

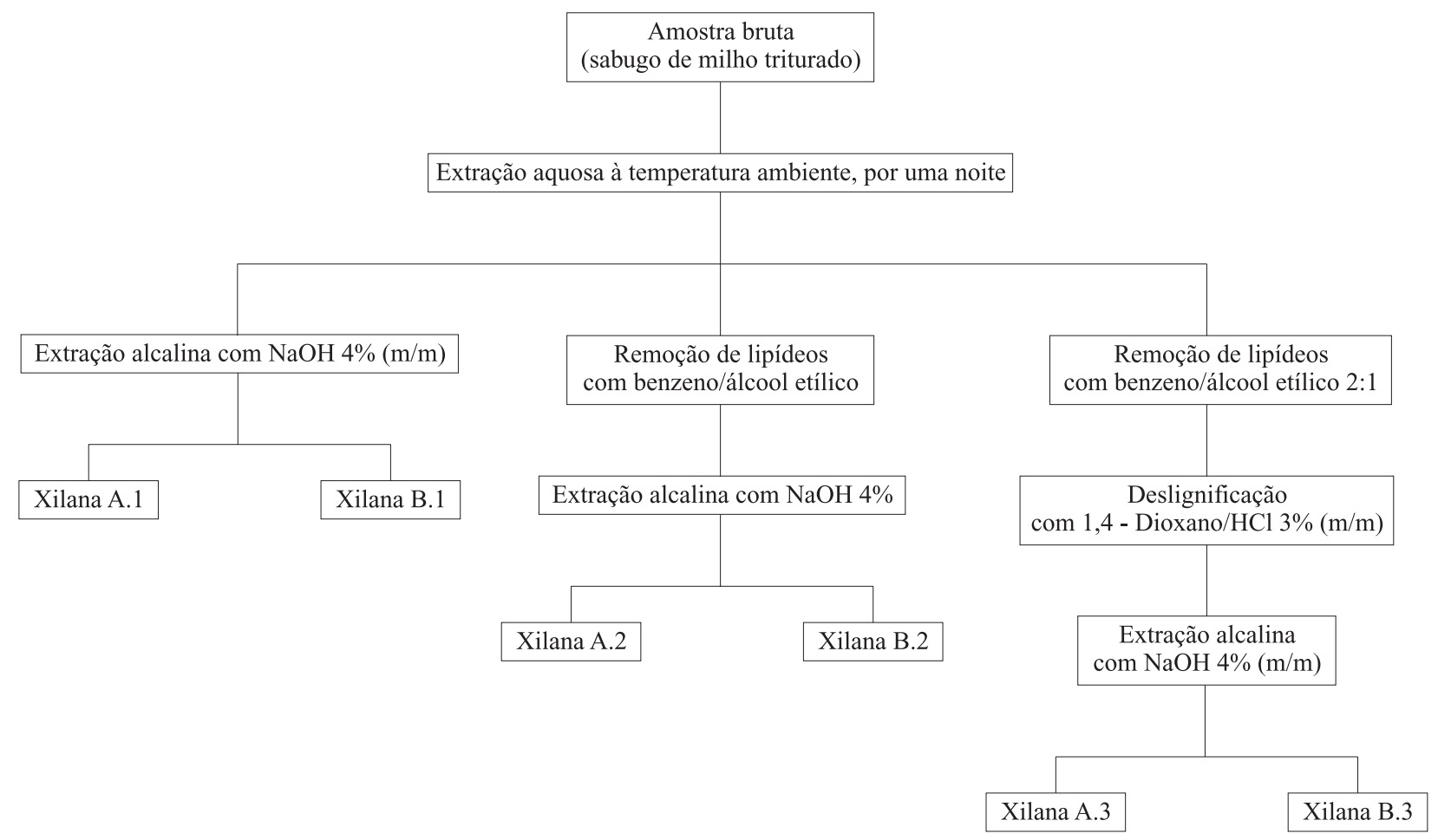

Figura 3. Esquema do processo de obtenção das xilanas 
sa residual observada ou não após centrifugação e secagem sob vácuo. Nos casos em que o polímero manteve-se insolúvel, as soluções foram aquecidas a temperaturas próximas à ebulição dos solventes.

\section{Métodos analíticos}

\section{Determinação do teor de lignina}

O teor de lignina dos sabugos de milho utilizados neste trabalho, antes e após a deslignificação, foi determinado de acordo com a norma ASTM D1106$56^{[18]}$. A concentração de lignina nas amostras xilana A.2 e xilana B.2 foi determinada por espectroscopia no ultravioleta com espectrofotômetro Hitachi U2000, em $\lambda=283 \mathrm{~nm}$, utilizando DMSO como solvente e o valor médio de $14,5 \mathrm{~L} / \mathrm{cm} . \mathrm{g}$ como absortividade da lignina ${ }^{[19]}$.

\section{Espectroscopia na região do infravermelho}

Os espectros foram obtidos através de filmes dos polissacarídeos, em um espectrofotômetro FTIR MIDAC Prospect, no intervalo de 4000 a $400 \mathrm{~cm}^{-1}$. Os filmes foram preparados vertendo-se as soluções de xilana em DMSO à concentração de $5 \mathrm{~g} / \mathrm{L}$, sobre placas de teflon. $\mathrm{O}$ sistema foi mantido em câmara termostatizada a $50^{\circ} \mathrm{C}$ por três dias até a completa evaporação do solvente. Os filmes obtidos foram mantidos em dessecador até o momento da análise por infravermelho.

\section{Termogravimetria}

Um estudo da estabilidade térmica de algumas amostras foi realizado através de termogravimetria, empregando uma termobalança TGA-7 da Perkin Elmer, à velocidade de aquecimento de $5^{\circ} \mathrm{C} / \mathrm{min}$, no intervalo de 40 a $940{ }^{\circ} \mathrm{C}$, utilizando massas de amostras em torno de $10 \mathrm{mg}$ e atmosfera de nitrogênio.

\section{Viscosimetria}

A análise viscosimétrica das amostras xilana A.2 e xilana B.2 foi realizada em DMSO, utilizando um reômetro digital Brookfield DV-III, equipado com jaqueta de termostatização e spindle $\mathrm{n}^{\mathrm{o}} 40$ - cone/prato. A temperatura das soluções foi mantida a $25^{\circ} \mathrm{C}$ por meio de um banho termostático de circulação de água. A viscosidade intrínseca foi determinada levando-se em consideração as viscosidades das soluções referentes às mais baixas velocidades de cisalhamento permitidas dentro do erro experimental e no platô newtoniano. As análises viscosimétricas foram feitas em duplicata e a partir de soluções filtradas através de membranas Millipore de diâmetro de poro $0,8 \mu \mathrm{m}$.

\section{Resultados e Discussão}

A Tabela 1 apresenta as variações em massa sofridas pelos sabugos de milho triturados, em cada tratamento.

A extração aquosa resultou, em média, em perda de massa de 5,73\%. Esta perda foi atribuída à eliminação de produtos orgânicos e inorgânicos de baixa massa molecular solúveis em água. Embora tenham sido encontradas na literatura informações sobre a presença de uma fração de xilana solúvel em água em algumas espécies vegetais ${ }^{[7,12,13]}$, não foi detectada a presença da mesma no extrato aquoso. Após adição de álcool etílico a esse extrato, não foi observada nenhuma precipitação de polímero.

A perda de massa na extração com benzeno/álcool etílico ficou em torno de 10,55\%. A mesma foi atribuída à remoção de lipídeos, ceras e pigmentos. Sabe-se que os lipídeos não são completamente removidos por solventes hidrofóbicos, tais como éter ou benzeno, porque esses solventes não são capazes de penetrar em todas as partes da estrutura da planta. Solventes hidrofílicos, tais como álcool etílico, removem, além de lipídeos, uma variedade de outros constituintes, como carboidratos de baixa massa molecular. Assim, através de uma mistura de solventes do tipo hidrofóbico e hidrofílico, como benzeno e álcool etílico, pôde-se combinar as vantagens de ambos.

Como pode ser observado ainda na Tabela 1, a deslignificação realizada foi responsável por uma

Tabela 1. Perda de massa durante o isolamento das xilanas, $\% \mathrm{~m} / \mathrm{m}$.

\begin{tabular}{lc}
\hline \multicolumn{1}{c}{ Etapa } & $\boldsymbol{\delta} \mathbf{m}=\left(\mathbf{m}_{\text {inicial }}-\mathbf{m}_{\text {final }}\right) / \mathbf{m}_{\text {inicial }} \mathbf{x} \mathbf{1 0 0}$ \\
\hline $\begin{array}{l}\text { Extração aquosa } \\
\text { Extração benzeno/ álcool } \\
\text { etílico }\end{array}$ & 5,73 \\
Deslignificação & 10,55 \\
\hline
\end{tabular}

*Dado obtido para 4 horas de deslignificação 
Tabela 2. Variação da perda de massa com o tempo de deslignificação e o teor de lignina correspondente.

\begin{tabular}{ccc}
\hline $\begin{array}{c}\text { Tempo de } \\
\text { deslignificação } \\
\text { (h) }\end{array}$ & $\begin{array}{c}\text { Perda de massa } \\
(\boldsymbol{\%} \mathbf{~ m} / \mathbf{m})\end{array}$ & $\begin{array}{c}\text { Teor de lignina } \\
(\% \mathbf{~ m} / \mathbf{m})\end{array}$ \\
\hline 1 & 59,65 & 10,70 \\
2 & 63,33 & 11,00 \\
4 & 55,77 & 12,50 \\
\hline
\end{tabular}

grande perda de massa $(55,77 \%)$, que não está de acordo com o teor de lignina de $18,8 \%$ determinado para o sabugo utilizado neste trabalho. Esse resultado pode ter ocorrido devido à hidrólise parcial dos polissacarídeos, especialmente das xilanas, que apresentam grande susceptibilidade à despolimerização em meio ácido. Dessa forma, tornou-se necessário realizar um estudo sobre o tempo ideal para o processo de deslignificação. Os resultados deste estudo estão contidos na Tabela 2 .

Como pode ser observado na Tabela 2, as perdas de massa ocorridas durante a deslignificação por 1,2 e 4 horas foram praticamente as mesmas, assim como o teor de lignina residual no produto obtido. Esses resultados indicam que o processo de deslignificação com dioxano- $\mathrm{HCl}$ promove perda acentuada de material mesmo com 1 hora de tratamento, e a redução do teor de lignina no sabugo é de aproximadamente $8 \%$ (tomando por base o valor do teor de lignina no sabugo antes do tratamento com dioxano- $\mathrm{HCl}, 18,8 \%$, e após o tratamento, $\approx 11 \%$ ), independente do tempo de tratamento.

A Tabela 3 mostra os rendimentos da extração alcalina na obtenção das diversas amostras de xilana. Em todos os processos, duas frações de xilana foram obtidas. A primeira surgiu após neutralização e conseqüente precipitação (xilana A). A segunda foi obtida pela precipitação ocorrida após adição de álcool etílico ao sobrenadante (xilana B). Os maiores rendimentos foram das amostras A.2 e B.2. Esse resultado, de certa forma, já seria esperado, já que o segundo processo ofereceu menor risco de degradação, quando comparado ao terceiro processo, e maior facilidade de solubilização das xilanas, devido à remoção de extrativos organo-solúveis com benzeno/álcool etílico, que não ocorreu no primeiro processo. $\mathrm{O}$ terceiro processo foi o que apresentou os menores rendimentos em relação à amostra bruta. Provavelmente, esse resultado ocorreu devido à degradação parcial da xilana, como já discutido anteriormente. É interessante observar a relação entre os rendimentos dos três processos. Os dois primeiros processos apresentaram maior rendimento para as amostras B (B.1 e B.2), que foram equivalentes entre si. Isso pode ser explicado pela maior solubilidade dos polissacarídeos dessa fração, por apresentarem, freqüentemente, maior grau de substituição ${ }^{[1]}$. O maior rendimento de A.2, com relação a A.1, pode ter ocorrido pelo efeito da extração com benzeno-álcool etílico, favorecendo o acesso da solução alcalina. No terceiro processo, o rendimento maior foi observado para a fração A. A maior facilidade de extração (solubilização) da xilana B da parede celular pode também explicar a sua maior vulnerabilidade frente à hidrólise ácida, diminuindo o seu rendimento.

O teor de lignina determinado para as xilanas A.2 e B. 2 foi de $26,91 \%$ e $24,35 \%$, respectivamente. A presença de lignina nas amostras de xilana poderia ser explicada pela sua parcial solubilidade em soluções aquosas alcalinas ou por estar ligada quimicamente à xilana. Alguns experimentos ainda estão sendo realizados com o objetivo de esclarecer o fato.

Os espectros no infravermelho das xilanas A.2 e B.2 são apresentados na Figura 4. Não foram observadas diferenças significativas entre os dois espectros, o que significa que os dois polissacarídeos devem apresentar, qualitativamente, a mesma composição química. Tanto a xilana A como a B apresentaram as bandas de absorção discriminadas a seguir. Banda larga centrada em torno de $3500 \mathrm{~cm}^{-1}$, atribuída à deformação axial O-H; $2923 \mathrm{~cm}^{-1}$, deformação axial C$\mathrm{H} ; 1646 \mathrm{~cm}^{-1}$, deformação angular $\mathrm{H}-\mathrm{O}-\mathrm{H}$ característica de água; $1415 \mathrm{~cm}^{-1}$, deformação angular de $\mathrm{CH}_{2} ; 1041 \mathrm{~cm}^{-1}$, referente às vibrações do anel glicosídico, deformação angular C-O-H, deformação axial C-O e C-O-C; $896 \mathrm{~cm}^{-1}$, deformação angular $\mathrm{C}-\mathrm{H}$ do carbono anomérico $\beta$ e $652 \mathrm{~cm}^{-1}$, deforma-

Tabela 3. Rendimentos da extração alcalina, $\%$ m/m.

\begin{tabular}{l|cccccc}
\hline $\begin{array}{c}\text { Rendimento } \\
(\% \mathbf{m} / \mathbf{m})\end{array}$ & $\begin{array}{c}\text { Xilana } \\
\text { A.1 }\end{array}$ & $\begin{array}{c}\text { Xilana } \\
\text { B.1 }\end{array}$ & $\begin{array}{c}\text { Xilana } \\
\text { A.2 }\end{array}$ & $\begin{array}{c}\text { Xilana } \\
\text { B.2 }\end{array}$ & $\begin{array}{c}\text { Xilana } \\
\text { A.3* }\end{array}$ & $\begin{array}{c}\text { Xilana } \\
\text { B.3* }\end{array}$ \\
\hline $\begin{array}{l}\text { Em relação à } \\
\text { amostra do } \\
\text { tratamento } \\
\text { anterior à } \\
\text { extração } \\
\text { alcalina }\end{array}$ & 6,55 & 19,67 & 11,96 & 19,62 & 11,20 & 4,72 \\
$\begin{array}{l}\text { Em relação à } \\
\text { matéria bruta }\end{array}$ & 4,94 & 14,84 & 9,39 & 15,40 & 3,78 & 1,59 \\
\hline
\end{tabular}

* tempo de deslignificação=4 horas 

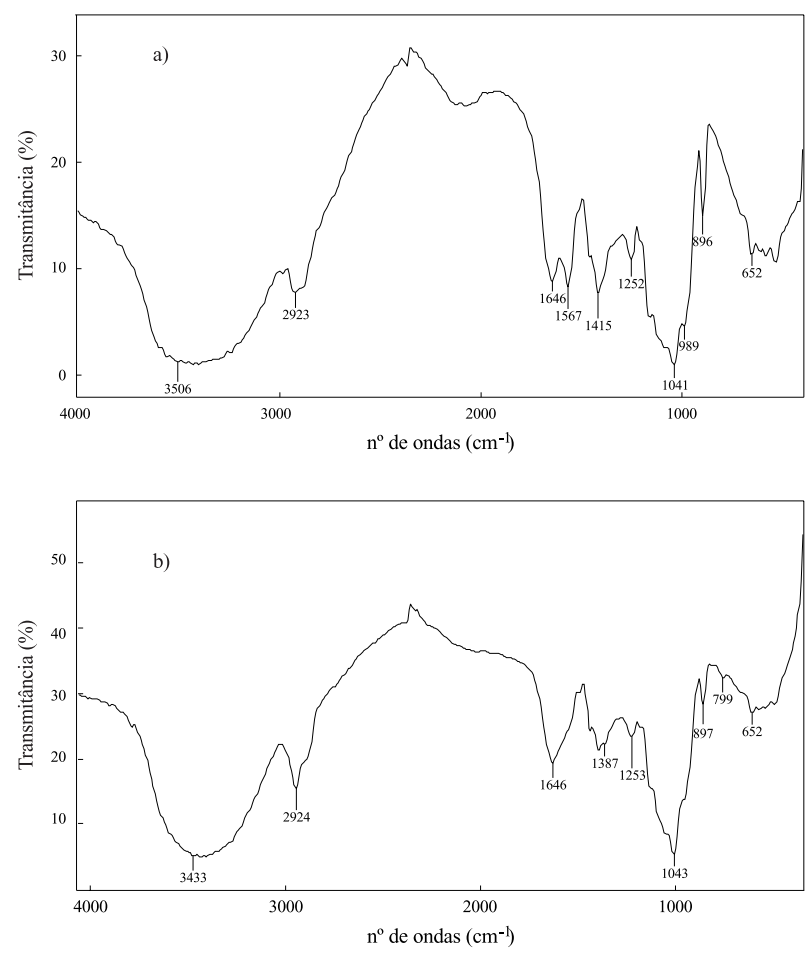

Figura 4. Espectros de absorção no infravermelho das xilanas A.2 (a) e B.2 (b).

ção angular O-H ${ }^{[20]}$. A banda observada em $1567 \mathrm{~cm}^{-1}$, no espectro da xilana $\mathrm{A}$, poderia ser atribuída à lignina residual no polissacarídeo (deformação axial $\mathrm{C}=\mathrm{C}$ de anel aromático), que estaria presa ao polissacarídeo por ligações físicas ou químicas. É possível que essa banda esteja em menor intensidade no espectro da xilana B e, por isso, tenha sido obscurecida pela banda de água vizinha, a $1646 \mathrm{~cm}^{-1}$. As demais bandas características da lignina ${ }^{[21]}$ teriam sido mascaradas pelas bandas da xilana.

Pode-se observar ainda que em nenhum dos dois espectros há a absorção característica da deformação axial da carbonila dos ácidos carboxílicos, em torno de $1730 \mathrm{~cm}^{-1}$. Isso indica a ausência de resíduos de ácidos urônicos nas xilanas. A banda centrada em $1041 \mathrm{~cm}^{-1}$, referente às vibrações do anel glicosídico, deformação angular C-O-H, deformação axial C-O e $\mathrm{C}-\mathrm{O}-\mathrm{C}$, apresenta perfil semelhante a das arabinoxilanas com baixo grau de substituição ${ }^{[6]}$.

A Tabela 4 apresenta os resultados obtidos dos testes de solubilidade realizados para as xilanas A.2 e B.2. Pôde-se verificar solubilidade desses polissacarídeos apenas em solventes bastante polares, como DMSO e solução aquosa de uréia a $6 \mathrm{~mol} / \mathrm{L}$.

Com base nos dados apresentados na Tabela 4, tentou-se extrair as xilanas da matéria bruta (sabugos de milho) com uréia $6 \mathrm{~mol} / \mathrm{L}$. O resultado obtido não
Tabela 4. Testes de solubilidade das xilanas

\begin{tabular}{|c|c|c|}
\hline \multirow{2}{*}{ Solvente } & \multicolumn{2}{|c|}{ Amostra } \\
\hline & Xilana A.2 & Xilana B.2 \\
\hline Uréia $2 \mathrm{~mol} / \mathrm{L}$ & $\begin{array}{c}\text { parcialmente } \\
\text { solúvel a quente }\end{array}$ & $\begin{array}{c}\text { parcialmente } \\
\text { solúvel a quente }\end{array}$ \\
\hline Uréia 4 mol/L & $\begin{array}{c}\text { parcialmente } \\
\text { solúvel a quente }\end{array}$ & $\begin{array}{c}\text { parcialmente } \\
\text { solúvel a quente }\end{array}$ \\
\hline Uréia 6 mol/L & solúvel a quente & solúvel a quente \\
\hline DMA & insolúvel & insolúvel \\
\hline Piridina & insolúvel & insolúvel \\
\hline DMSO & solúvel a frio & solúvel a frio \\
\hline $\begin{array}{l}\text { Cloreto de metileno/ } \\
\text { Cloreto de etileno } 2: 1\end{array}$ & insolúvel & insolúvel \\
\hline
\end{tabular}

foi satisfatório, pois a quantidade removida de xilana foi muito pequena. Esse fato concorda com a idéia de que as xilanas podem estar ligadas aos demais componentes da parede celular também por ligações químicas, e não apenas por ligações hidrogênio, como se pensava inicialmente.

As Figuras 5 a 11 apresentam as curvas TGe suas respectivas derivadas (DTG) dos produtos obtidos durante o isolamento das xilanas. Pode-se notar que todas as curvas TG apresentaram, em média, perdas de massa em três intervalos de temperatura: de 30 a $130^{\circ} \mathrm{C}$, de 130 a $400^{\circ} \mathrm{C}$ e de 400 a $850^{\circ} \mathrm{C}$. A primeira perda foi associada à evaporação da água, a segunda à decomposição térmica dos polissacarídeos e a terceira à decomposição da lignina (ou de seus resíduos) e produtos estáveis da pirólise dos polissacarídeos.

Pode-se notar que o sinal da $1^{\text {a }}$ derivada das Figuras 5 a 7 , no intervalo de 130 a $400^{\circ} \mathrm{C}$, apresentou uma tendência de desmembramento em 2 picos, o que pode significar a presença de compostos diferentes sofrendo decomposição térmica. É possível que

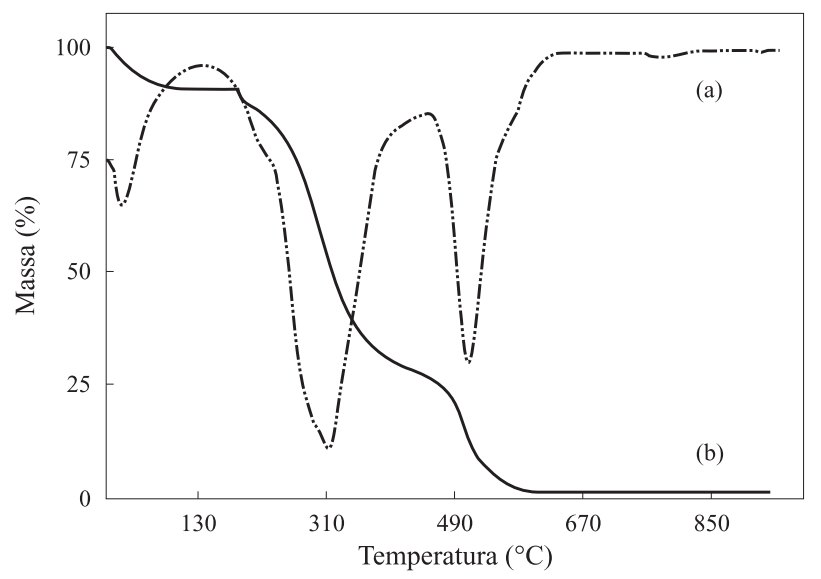

Figura 5. Curvas DTG (a) TG (b) da matéria bruta (sabugos de milho). 


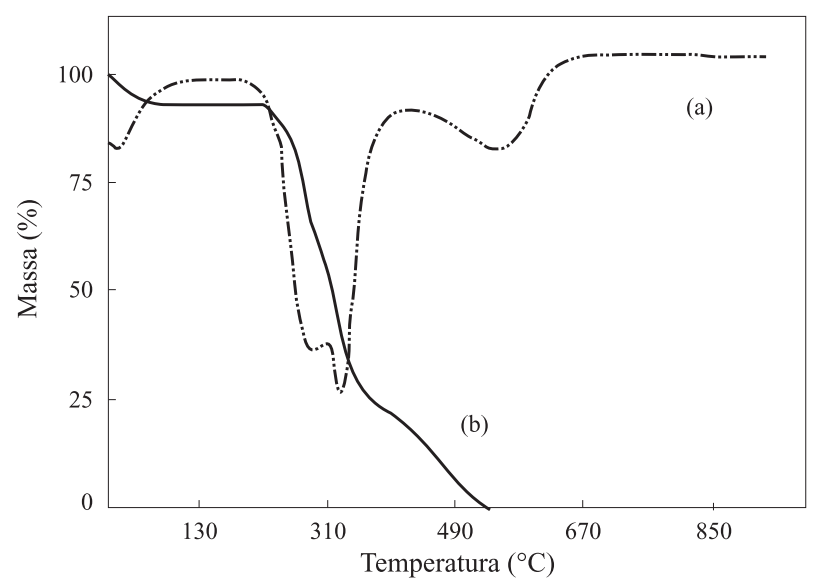

Figura 6. Curvas DTG (a) TG (b) da amostra após extração aquosa.

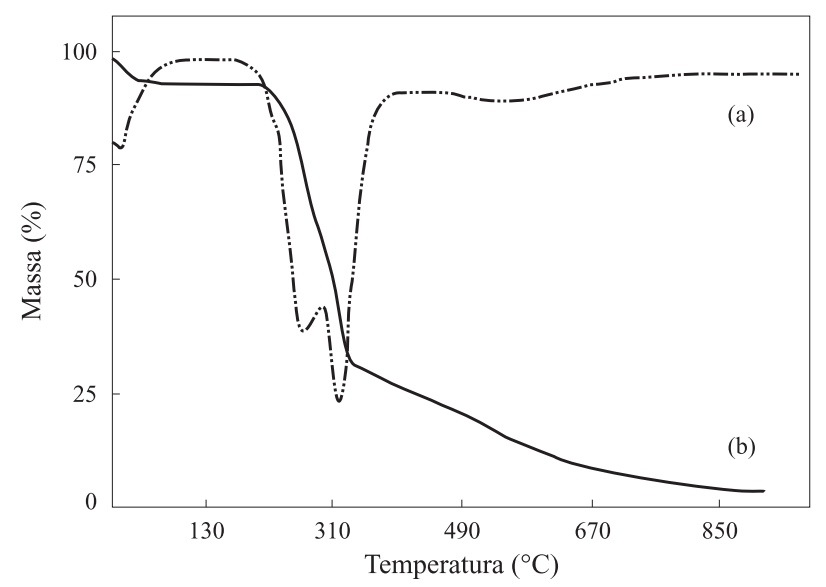

Figura 7. Curvas DTG (a) TG (b) da amostra após remoção dos lipídeos.

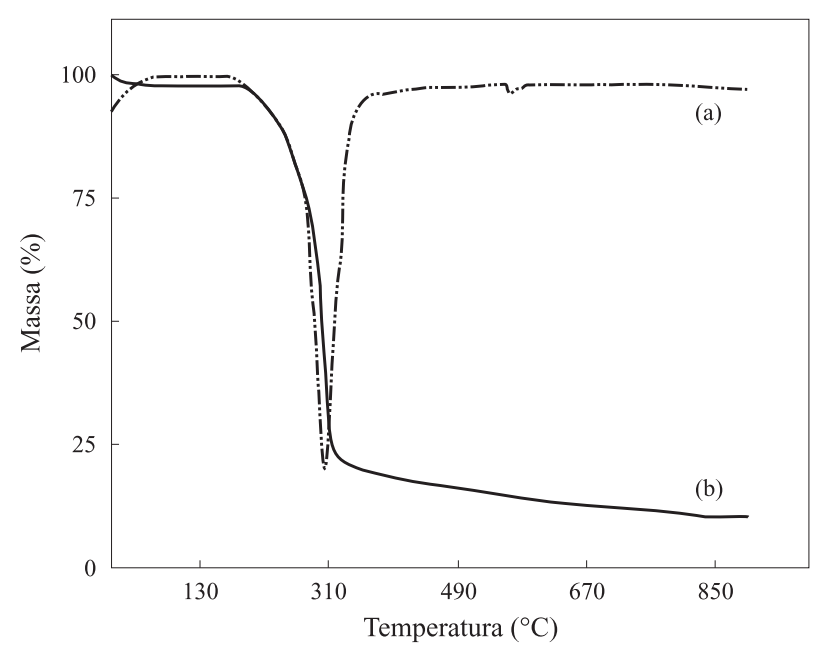

Figura 8. Curvas DTG (a) TG (b) da amostra após deslignificação.

esses compostos sejam a celulose e as xilanas que, durante o processo de extração, foram gradativamente sofrendo uma "parcial" separação. Após o processo de deslignificação (Figura 8), a curva da $1^{a}$ derivada, no intervalo de temperatura em discussão, apresentou apenas 1 pico. Esse resultado, quando associado

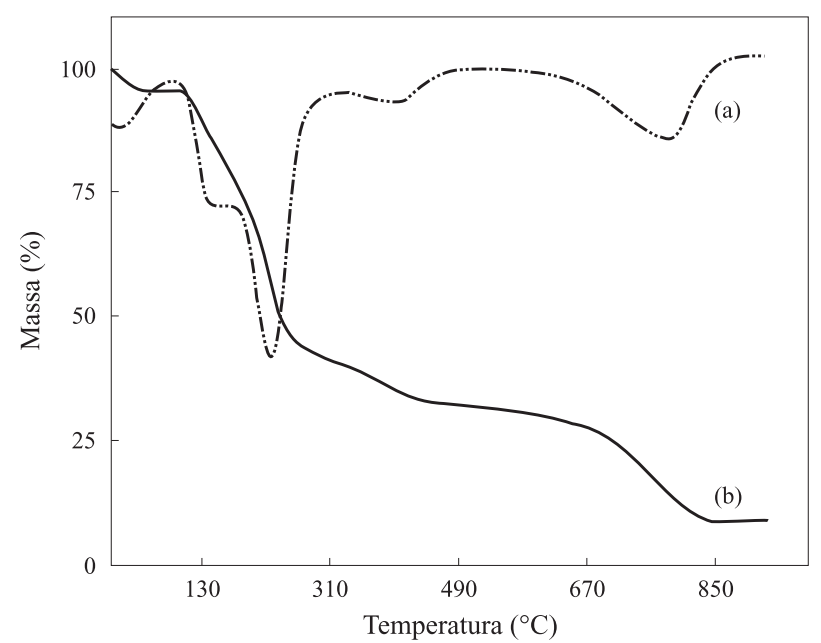

Figura 9. Curvas DTG (a) TG (b) da xilana A.3.

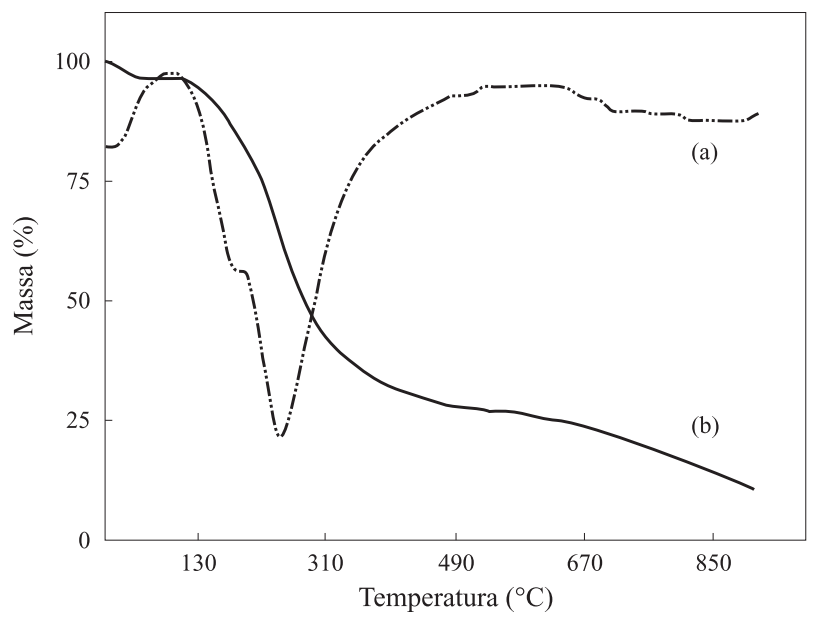

Figura 10. Curvas DTG (a) TG (b) da xilana B.3.

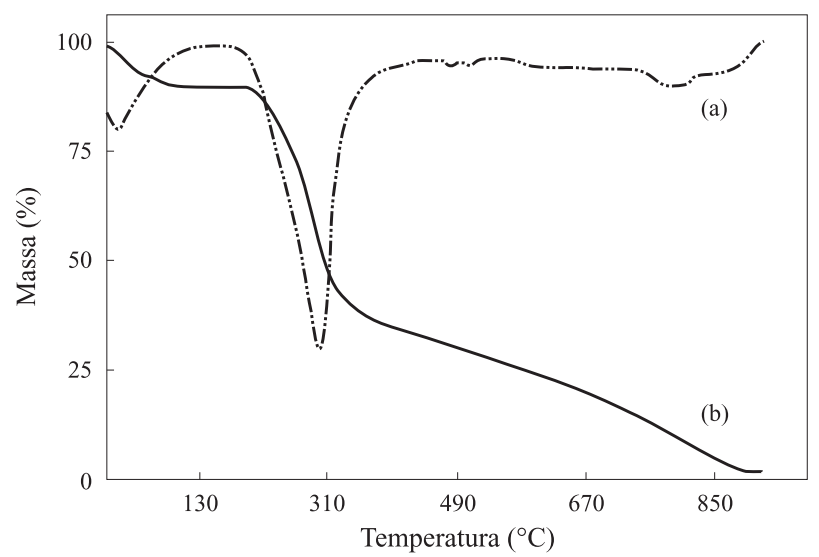

Figura 11. Curvas DTG (a) TG (b) da xilana B.2.

às observações anteriores de perda de massa, pode indicar que o pico observado apresenta uma contribuição significativamente maior da celulose, devido à degradação parcial das xilanas pelo meio ácido.

As curvas DTG obtidas para as frações de xilana A.3 e B.3 (Figuras 9e 10) apresentaram deslocamento 


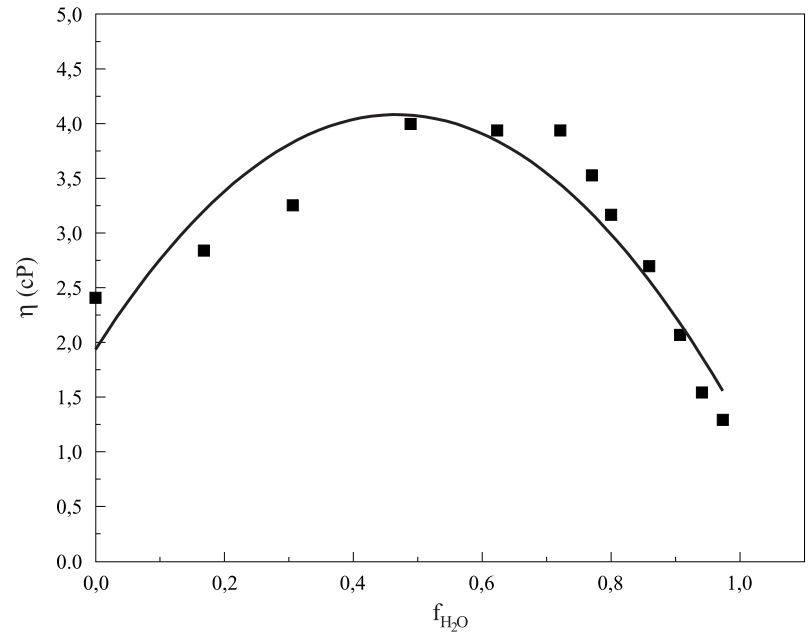

Figura 12. Variação da viscosidade de soluções de xilana B a 1,0 g/L em função da fração molar da água em DMSO, medida à velocidade de cisalhamento $100 \mathrm{~s}^{-1}$.

do pico observado no intervalo de 130 a $400^{\circ} \mathrm{C}$ para temperaturas mais baixas. Esse deslocamento poderia ser atribuído à queda de massa molecular das xilanas, devido à deslignificação.

Comparando as curvas DTG das Figuras 10 e 11 referentes às xilanas B.3 e B.2, podemos observar que a temperatura de máxima decomposição térmica da xilana B.2 é maior que a da B.3, o que concorda com o efeito de degradação, na etapa de deslignificação, discutido anteriormente.

A utilização de DMSO como solvente para a análise viscosimétrica das xilanas exigiu que alguns experimentos fossem realizados, com o objetivo de se verificar o efeito da absorção de umidade pelo DMSO sobre as medidas de viscosidade. Assim, a soluções de xilana B em DMSO de concentração 10,0 g/L adicionou-se volumes pré-determinados de água, de maneira a formar

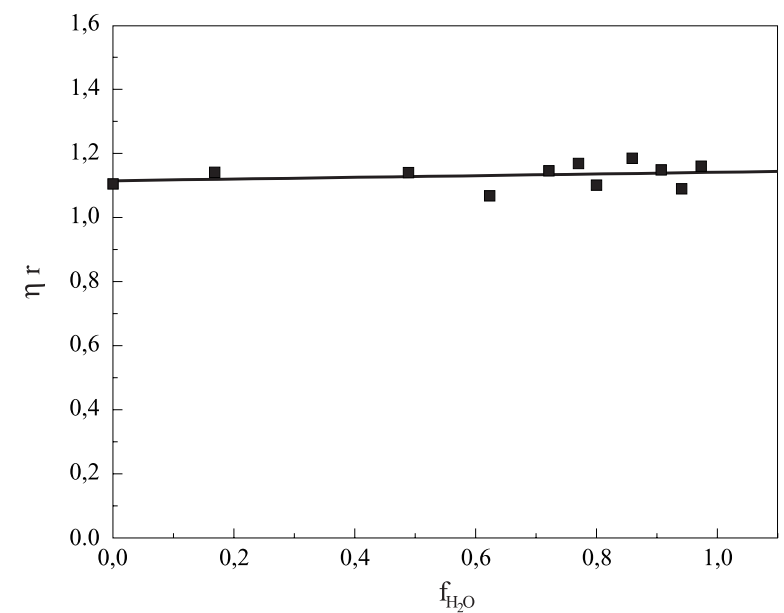

Figura 13. Variação da viscosidade relativa de soluções de xilana $B$ a $1,0 \mathrm{~g} / \mathrm{L}$ em função da fração molar da água em DMSO, medida à velocidade de cisalhamento $100 \mathrm{~s}^{-1}$. soluções de diferentes frações molares de água e concentração de polímero $1,0 \mathrm{~g} / \mathrm{L}$. Os resultados obtidos de viscosidade podem ser observados na Figura 12. De fato, nota-se um aumento sinérgico de viscosidade com a adição de água ao meio, que poderia ser atribuído à orientação das moléculas de água em torno do DMSO, formando estruturas organizadas responsáveis pelo aumento da viscosidade do solvente ${ }^{[22,23]}$. Essa interpretação pôde ser reforçada ao se verificar o comportamento da viscosidade relativa das mesmas soluções, mostrado na Figura 13. Nesta figura, verifica-se que a viscosidade relativa não é afetada significativamente pela presença de água no meio. Dessa forma, considerou-se que a determinação da viscosidade intrínseca das soluções de xilana não seriam perturbadas pela eventual presença de água no solvente, já que a sua determinação parte de valores de viscosidade relativa. Além disso, as medidas viscosimétricas são realizadas em sistema fechado (é utilizada uma jaqueta de termostatização) e o tempo requerido para a medição da viscosidade é pequeno, não tendo sido verificada nenhuma variação significativa de viscosidade do DMSO nesse período.

A Figura 14 apresenta a variação da viscosidade reduzida com a concentração para as xilanas A.2 e B.2. De acordo com a equação de Huggins ${ }^{[24]}$, que estabelece a relação entre a viscosidade reduzida e a concentração de um polímero em determinado solvente, $\eta_{\text {red }}=[\eta]+K^{\prime}[\eta]^{2} c$, a viscosidade intrínseca pode ser obtida através da extrapolação dos dados de viscosidade à diluição infinita. Dessa forma, foram obtidos os valores de viscosidade intrínseca de $56 \mathrm{~mL} / \mathrm{g}$ para xilana A.2 e $75 \mathrm{~mL} / \mathrm{g}$ para xilana B.2. Esse resultado pode indicar que a principal diferença

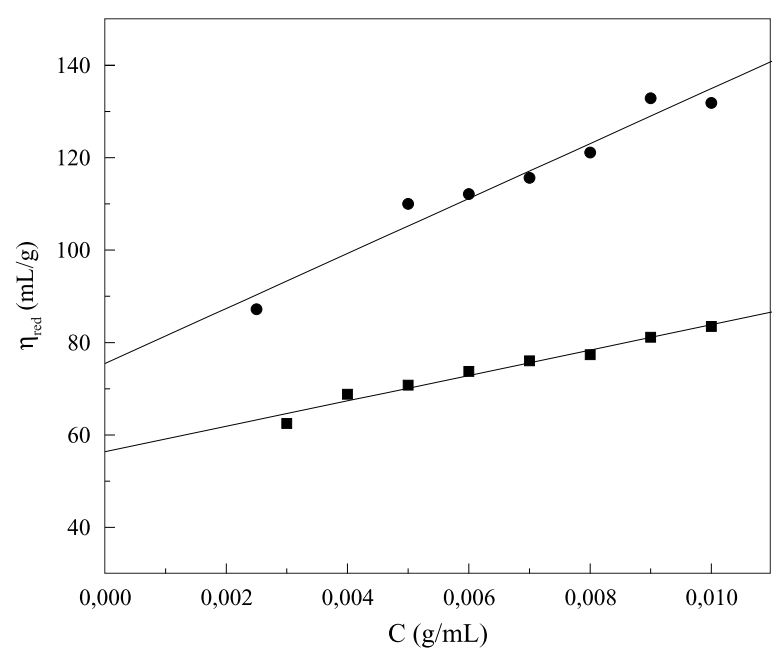

Figura 14. Variação da viscosidade reduzida com a concentração para

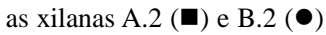


entre as duas xilanas consiste no maior volume hidrodinâmico da xilana B.2, promovido pelo maior número de substituintes (L-arabinose). A presença de substituintes tende a aumentar a rigidez da cadeia polimérica, assim como provocar repulsões estéricas, que seriam então responsáveis pelo maior volume hidrodinâmico e viscosidade intrínseca da xilana B.2.

\section{Conclusões}

Pôde-se verificar neste trabalho a grande susceptibilidade de hidrólise das xilanas em meio ácido durante a etapa de deslignificação. As amostras que não passaram por essa etapa apresentaram um rendimento global em xilana de $24,79 \%$. A análise em conjunto dos resultados obtidos de viscosidade intrínseca, infravermelho e o fato da xilana B permanecer em solução após a neutralização, na etapa de extração alcalina, sugere que a principal diferença entre as xilanas A e B dos sabugos de milho encontra-se no grau de substituição em resíduos de L-arabinose, que deve ser maior para a xilana B.

\section{Agradecimentos}

Os autores agradecem ao CNPq, CAPES e PPPgUFRN pelo apoio financeiro recebido.

\section{Referências Bibliográficas}

1. Whistler, R.L. e Smart, C.L. - "Polysaccharide Chemistry", cap IV, Academic Press Inc., New York (1953).

2. Whistler, R.L. e Richards, E.L. - "Hemicelluloses" em The Carbohydrates - Chemistry and Biochemistry, Pigman W. e Horton D. ed., vol IIA, Academic Press, New York, 447-469 (1970).

3. Chanda, S.K.; Hirst, E.L.; Jones, J.K.N. e Percival, E.G.V. - J. Chem. Soc., 1289-1297 (1950).

4. Reicher, F.; Corrêa, J.B.C. e Gorin, P.A.J. “Carbohydr. Res.”, 135, 129-140 (1984).

5 Kwan, J.S. e Morvan, H. - Carbohydr. Polym.,26, 99-107 (1995).

6. Kacuráková, M.; Ebringerová, A., Hirsch, J. e Hromádková, Z., J. - Sci. Food Agric., 66,423427 (1994).
7. Hoseney, R.C. e Faubion, J.M. - Cereal Chem.,58,421424 (1981).

8. Ishii, T. - Carbohydr. Res.,219, 15-22 (1991).

9. Ebringerová, A.; Hromádková, Z. e Berth, G. Carbohydr. Res., 264,97-109 (1994).

10. Saulnier, L.; Marot, C.; Chanliaud, E. e Thibault, J-F. - Carbohydr. Polym., 26, 279-287 (1995).

11. Mc Killip, W.J. e Sherman, E., Kirk-Othmer Encyclopedia of Chemical Technology, M. Grapson ed., vol 11, John Wiley \& Sons, 499-527, New York (1980).

12. Jelaca, S.L. e Hlynka, I. - Cereal Chem., 48,211222 (1971).

13. Jelaca, S.L. e Hlynka, I. - Cereal Chem.,49, 489495 (1972).

14. Kim, S.K. e D'Appolonia, B.L. - Cereal Chem., 54, 225-229 (1977).

15. Ebringerová, A.; Hromádková, Z.; Kacuraková, M. e Antal, M. - Carbohydr. Polym., 24, 301-308 (1994).

16. Ghose, T.K.; Pannir, P.V. e Gosh, P. - Biotechnology and Bioengineering, vol XXV, 2577-2590 (1983).

17. Janshekar, H. e Fiechter, A. - Advances in Biochemical Engineering, 27, 119-178 (1983).

18. Método ASTM D1106-56 - Annual Book of ASTM Standards, part 22, 342-343 (1975).

19. Lebel, R. G.; Goring, D.A.I. e Timell, T.E. - J. Polymer Sci., part C.2, 9-28 (1963).

20. Jerez, J. R.; Matsuhiro, B. e Urzúa, C.C. Carbohydr. Polym. ,32, 155-159 (1997).

21. Rohella, R. S.; Sahoo, N., Paul, S.C., Choudhury, S. e Chakravortty, V. - Thermochim. Acta, 287, 131-138 (1996).

22. Paker, K. J. e Tomlinson, D. J. - Trans. Faraday Soc., 67, 1302-1314 (1971).

23. Schichman, S.A. e Amey, R.L. - J. Phys, Chem., 75(1), 98-102 (1971).

24. Huggins, M.L. - J. Am. Chem. Soc., 64, 27162718 (1942).

Recebido: 20/03/97

Aprovado: 02/04/98 